\title{
Innovative process and technology for the production of wood mulch
}

\author{
Lorenzo Fiorineschi, ${ }^{1}$ Federico Rotini, ${ }^{1}$ Giuseppe Rossi, ${ }^{2}$ Leonardo Conti ${ }^{2}$ \\ ${ }^{1}$ Department of Industrial Engineering, University of Florence; ${ }^{2}$ Department of Agricultural, Food and Forestry \\ Systems, University of Florence, Italy
}

\begin{abstract}
Plant nurseries usually control weed growth with N-(phosphonomethyl) glycine treatment. Some studies have suggested potential impacts of this treatment on both the environment and users. A possible ecological alternative is the use of ground wood particles for mulching. However, the production of the required wood particles for use in potted plants is challenging. In this article, the classical chipping and sieving process is compared with a new proposed process involving chipping and refining phases. The two processes were applied to wood logs (spruce) from the forests of the Tosco-Emiliano Apennine. The tests were performed over a week using the machinery available at the Mo.To.R.E. (Montagna Toscana Ricerca Energie) consortium. Although the results achieved were based on preliminary evaluations, they indicated the potential superiority of the new process in terms of both economic and ecological efficiency. These findings can pave the way to the development of optimized processes aimed at a significant reduction in the use of chemical herbicides for weed control.
\end{abstract}

\section{Introduction}

Plant nurseries constantly face the challenge of controlling

Correspondence: Lorenzo Fiorineschi, Department of Industrial Engineering, University of Florence, via di S. Marta 3, 50139 Florence, Italy.

Tel.: +39.055.2758.709.

E-mail: lorenzo.fiorineschi@unifi.it

Key words: Glyphosate; nursery innovation; plant nursery; potted plants; wood chips.

Acknowledgements: the work described in this article has been partially supported by 'Fondazione Cassa di Risparmio di Pistoia e Pescia', with the funding programme named 'Bando Giovani e Ricerca 2016'. We also thank the Stern Progetti Srl staff for the provided support.

Received for publication: 5 August 2020.

Accepted for publication: 7 November 2020.

${ }^{\circ}$ Copyright: the Author(s), 2021

Licensee PAGEPress, Italy

Journal of Agricultural Engineering 2021; LII:1111

doi:10.4081/jae.2021.1111

This article is distributed under the terms of the Creative Commons Attribution Noncommercial License (by-nc 4.0) which permits any noncommercial use, distribution, and reproduction in any medium, provided the original author(s) and source are credited. weed growth, which is highly undesirable, particularly after potting. For this purpose, glyphosate $\mathrm{N}$-(phosphonomethyl) glycine is widely used as an herbicide, because it is normally considered a non-toxic product. Nevertheless, several studies examined the potential impact on both the environment and users and reached conflicting conclusions on these risks (Acquavella et al., 2004). Even though the actual risks associated with the use of glyphosate remain unclear, bio-based alternatives to control weed growth are attracting greater interest. These alternatives include the use of ground wood particles for mulching (Chalker Scott, 2015), which may be a sustainable solution, particularly for areas with large forests. In particular, small wood chips have been used to hinder weed growth. This solution consists in depositing the wood chips into pots with semi-automatic devices (not described herein). Indeed, many thousands of pots per month are produced by larger factories. Manual deposition of chips is not used, because of economic sustainability problems.

The particle sizes of wood chips are quite small and irregular, and no specific size requirements have been provided at this stage, because different pot dimensions appear to require different particle sizes. For example, larger particles can be used in larger pots, thus providing benefits in terms of soil transpiration. However, nursery workers assert that the potting process can be problematic when larger chips are used in smaller pots. Therefore, an optimal wood mulch production process should be versatile and capable of producing different ranges of wood chips dimensions according to the different nursery requirements.

To reduce the costs of wood mulch, conifer species (e.g., pine and spruce) are currently used, owing to their low economic value, thus making them a valid candidate material. Accordingly, for potting mulch, the production of the required wood particles is known to be challenging (Febbi et al., 2013). However, although a standard set of requirements for this application is lacking, nursery users and consultants have provided some fundamental knowledge regarding particle size and wood species. In particular, the pot dimensions influence the size distribution of the wood particles. Moreover, wood species with a high tannin content (e.g., chestnut) must be avoided to prevent contamination of the soil in the pot and consequently the plant (Kannepalli et al., 2016).

Despite the lack of a robust set of requirements to generate a quality reference standard, the consortium involved in this work aimed to develop a sustainable process for the production of wood-chip mulch with the desired particle size distribution. Currently, no standard widespread process to produce wood-chip mulch are available. Therefore, the consortium considered firstly the classical chipping and sieving process, which is typically used for the production of micro-chip biofuel (Spinelli et al., 2018). Unfortunately, larger chips also remain present with this process and a sieving stage is necessary to separate the chips of the desired size from undersized and oversized chips. This aspect introduces an upper limit in terms of yield of final obtainable product, since the final product quantity is always a fraction of the total pro- 
cessed wood. Additionally, this process is highly dependent on fossil fuel, which is regarded as significant implication in terms of its related ecological impact. These issues led the consortium to think about possible and more efficient process alternatives. Therefore, a possible alternative to the classical chipping and sieving process, which has been recently proposed for microchip production, was considered for this purpose (Fiorineschi et al., 2020).

In this context, the aim of the work was to compare the classical chipping and sieving process with the alternative chipping and refining process, in terms of both economic and ecological efficiency.

\section{Materials and methods}

\section{Wood species used in this experiment}

The wood logs used for the experiments were extracted in the forests on the mountains above Pistoia (Tuscany, Italy), populated by a plethora of different wood species (e.g. chestnut, pine, spruce, beech, acacia, etc.). However, to reduce costs and avoid the presence of tannins, the wood chips obtained for this work were derived only from spruce logs, with diameters ranging prevalently from about $150 \mathrm{~mm}$ to $300 \mathrm{~mm}$. The chipping and refining processes were performed a couple of days after the cut, therefore with a moisture content of slightly more than $45 \%$ in mass.

\section{Current production process adopted by the consortium}

To produce the required particle sizes (according to the qualitative and subjective evaluations of the nursery operators), the consortium involved in this research followed a specific process, as described in Figure 1.

Wood logs were chipped with a conventional power take off drum chipper. To obtain the highest percentage of the approximate required dimensions, the chipper was set with a grid with opening dimensions of $30 \times 30 \mathrm{~mm}$, the minimum possible distance between the blades and the anvil, and the minimum log forward speed.

The produced wood chips were then sieved through a conventional vibrating screen, thus yielding three fractions: oversized chips, desired size chips and undesired finer particles. The power consumption of the sieve, which was powered by an electrical motor, was previously estimated by the consortium to be $0.6 \mathrm{kWh}$ for each stere cubic meter of processed wood chips. This value is comparable to those reported in the literature (Woo and Han, 2018), although those studies used diesel powered engines.

The desired particles were then directly stored in conventional large bags for distribution, whereas oversized particles underwent an additional process to produce high quality wood chips for combustion (M20-P45 according to the CEN/TS 14961:2005). In particular, oversized particles were dried in a conveyor belt drying oven heated by a boiler fed with low-cost coarse wood chips (M40P63 according to the CEN/TS 14961:2005). In particular, the consortium estimated a consumption of approximately $25 \mathrm{~kg}$ of coarse chips (used as fuel) to remove $20 \%$ of water from one steric cubic meter $\left(\mathrm{sm}^{3}\right)$ of processed biomass in line with data available from the literature (Haque and Somerville, 2013), if the heating value of coarse chips was approximately $10 \mathrm{MJ} / \mathrm{kg}$ (i.e., $2.8 \mathrm{kWh} / \mathrm{kg}$ ). Then, the dried wood chips were sieved again to eliminate larger wood pieces and generate the P45 size range. Finally, the high-quality chips were bagged in conventional large bags.

According to the estimates of the consortium, the current pilot process is capable obtaining the range of products reported in Table 1.

\section{Alternative process and related technologies}

According to Table 1, one of the main limits of the current process adopted by the consortium is the impossibility of transforming all the processed wood into the desired mulch, thus limiting economic profitability.

Therefore, an alternative simpler process was examined, in

Table 1. Product percentages obtained by the current process adopted by the consortium and related economical values expressed in terms of selling price for cube meter.

\begin{tabular}{lccc} 
& Wood mulch & High quality wood chips & Waste \\
Percentage & $70 \div 85 \%$ & $15 \div 20 \%$ & $1 \div 5 \%$ \\
Value & $50 € / \mathrm{sm} 3$ & $25 € / \mathrm{sm}^{3}$ & $0 € / \mathrm{sm}^{3}$ \\
\hline
\end{tabular}

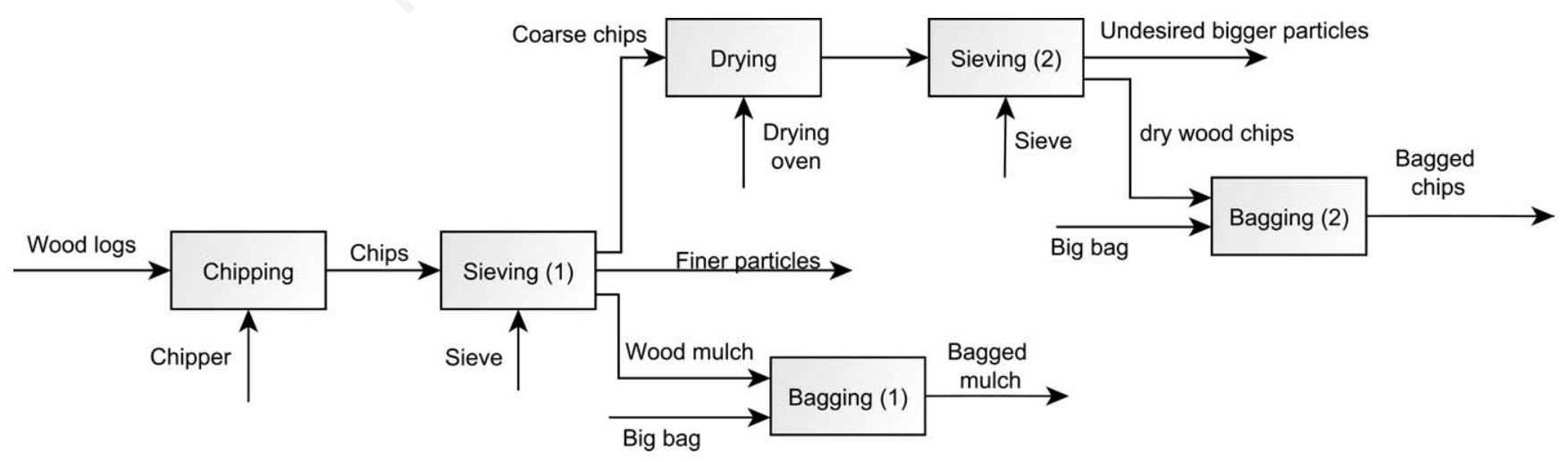

Figure 1. IDEF0 diagram of the current production process adopted by the consortium. Each box represents a key stage or function of the process. Horizontal arrows represent the input and the output of each stage, while the vertical arrows represent the devices that perform the required functions. 


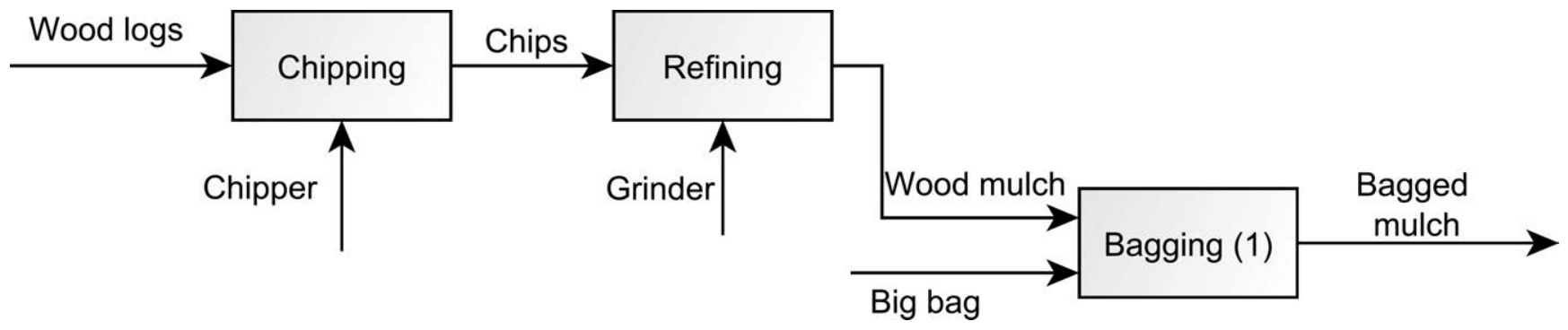

Figure 2. IDEF0 diagram of the alternative experimental process. Each box represents a key stage or function of the process. Horizontal arrows represent the input and the output of each stage, while the vertical arrows represent the devices that perform the required functions.

which, the chipper was set at its maximum productivity (i.e., the largest possible chip size). In particular, the chipper used a $50 \times 50$ $\mathrm{mm}$ mesh grid, the maximum allowable distance between the blades and anvil, and the maximum forward speed for wood logs. Regarding the forward speed, the hydraulic valve controlling log feeding was set to allow a compromise between forward speed and the frequency of backward log movement. After chipping, as shown in Figure 2, the obtained particles underwent a refining process performed with a particular grinder prototype. In this way, it was possible to bag the entire quantity of wood as wood mulch.

The grinder prototype was a multi-stage rotational and centrifugal grinder into which the raw material was introduced axially and then propelled across a static and rotational cutting stage (Fiorineschi et al., 2020). This specific grinder was tested for the production of microchips, but it can be used for many other applications (Fiorineschi et al., 2018).

It consists of internal propelling blades that pump air into the device and also impart a tangential motion to wood particles. Consequently, owing to the airflow and centrifugal force, the wood particles are forced to pass through the alternating stator and rotor blades that perform the cuts. The airflow also interacts with the alternating static and rotating elements of the comminution chamber, thereby producing pressure waves. Therefore, a sentry-siren effect was generated, with sound waves in the audible spectrum of approximately $100 \mathrm{~dB}$ measured at 1 meter distance (see Fiorineschi et al. (2020) for further details). The prototype was mounted on an aluminium frame, together with a $30 \mathrm{~kW} \mathrm{AC} \mathrm{motor}$ and related transmission belt. For testing different rotational speeds, the motor was powered with an inverter capable of setting current frequencies from 0 to $60 \mathrm{~Hz}$. The number of electrical poles of the motor (two) and the speed ratio provided by the transmission belt made it possible to reach a maximum rotational speed of 7200 rpm at $60 \mathrm{~Hz}$.

\section{Experimental setup}

\section{Measuring the diesel consumption of the chipper}

In order to compare the two processes in terms of energy consumption, we evaluated the differences between the chipper configurations in terms of fuel needs. For that purpose, a low-cost experimental layout (Figure 3) was used to produce samples of wood chips according to the settings of the two investigated processes. As shown in Figure 3, a hydraulic arm powered by a specific tractor was used to feed wood logs into the drum chipper, which was powered by another specific tractor. A forklift was used

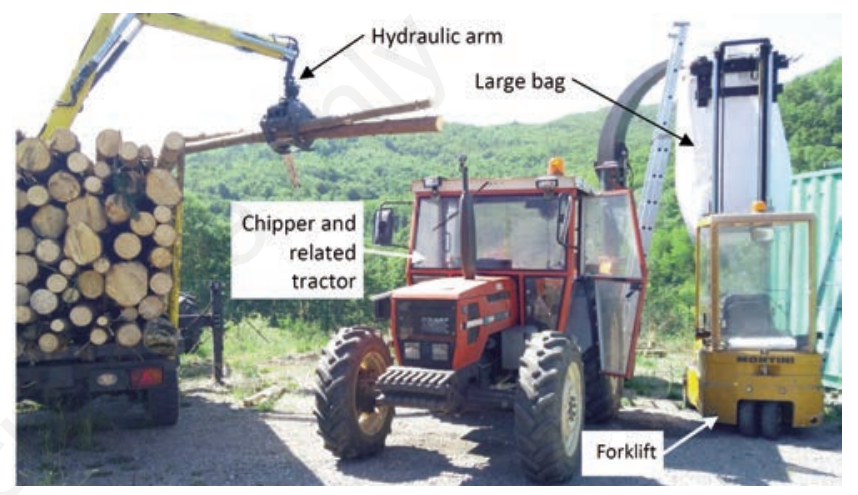

Figure 3. Experimental layout composed by a loader hydraulic arm, a drum chipper and a forklift to hold the big-bag. The latter was used only for experimental purposes.

to hold the large bag used to contain the samples, thus allowing us to control the volume of the produced chips (i.e., $1.5 \mathrm{sm}^{3}$ for each sample). The power consumption of the hydraulic arm and the forklift was not considered in the comparison, because it was identical in all the investigated settings. Table 2 shows the three factors and the related levels assigned for each investigated setting.

\section{Grinder experimental plant}

In order to determine the power consumption of the grinder, we designed an experimental plant whose main elements are depicted in Figure 4. A hopper with a feeding screw was used to contain the coarse woodchips and control the mass flow rate. Then an elevating screw brought the raw material to the inlet of the grinder comminution chamber. In the same inlet, an additional tube was connected to provide the necessary airflow. An outlet piping allowed the output material to reach the large bag used to collect the sample. An inverter was used to control the grinder rotation speed, whereas another specific inverter was used to control the rotation speed of the feeding screw (to control the mass flow rate of the raw material). Preliminary tests were performed to calibrate the feeding screw and determine the correlation between rotational speed and wood mass flow. Curves were obtained for processed wood chips with different moisture contents in order to identify the most suitable curves according to the actual moisture content of the processed chips. We used a commercial tool to measure rapidly the moisture content of the 
wood chips with different particle sizes and wood types (Schaller, n.d.) and determine the percentage moisture content $M$, according to the commercial standards (Equation 1):

$M=\frac{P_{u}-P_{o}}{P_{u}} \times 100$

where $P_{u}$ is the weight of the wet wood, and $P_{o}$ is the weight of the dry wood.

The power consumption was measured with an electrical power analyser (CVM/Mini: Asita Srl, Faenza (RA), Italy; https://www.asita.com/). Among the available data, the analyser provided the actual power consumption of the grinder in $\mathrm{kW}$. The mean power values were obtained as the arithmetical average of a predefined number of instantaneous power values.

\section{Characterization of particle size distributions and moisture content}

To characterize the particle size distributions of both the raw and processed material, we used a manual sieve with three different grids. The first grid had a square mesh with a side of $10 \mathrm{~mm}$, the second grid had a square mesh with a side of $5 \mathrm{~mm}$, and the third grid had a square mesh with a side of $2.5 \mathrm{~mm}$. The sieve was capable of processing samples of approximately $1 \mathrm{~kg}$. Moreover, a scale with a $0.0001 \mathrm{~kg}$ resolution was used to measure the weights of the produced samples. The particle size distribution for each configuration was assessed by sieving three samples. Then the weight of the material collected in each screen stage was measured and rounded to two decimal places (in $\mathrm{kg}$ ).

\section{Results}

\section{Comparison of the particle size distributions}

We observed that setting number 2 led to a greater (and quite variable) percentage of larger particles and fewer smaller particles. In particular, the Setting 2 generated a greater percentage of wood particles, but in an inconsistent way (as shown by the high standard deviations). This finding was expected, owing to the different factors and levels considered (Table 3). However, the differences in the settings were not substantial, because of the limited power of the considered chipper. Indeed, it was not possible to use larger mesh sizes or increase further the wood log forward speed.

The grinder prototype and the related experimental plant (see Grinder experimental plant section) were used to refine the wood chips produced by the chipper with setting 2 (Table 2). The obtained particles can be considered to indicate the outcome of the new proposed process (Figure 5).

The particle size distributions obtained with the two processes are shown in Table 4. As shown in Figure 6, the refining process reduced the percentage of larger particles, but caused a limited increase in the smallest particles. This characteristic of the considered grinder is relevant to the preliminary nursery requirements. The two types of mulch ultimately obtained with the two processes are depicted in Figure 7. The forms of the particles obtained were

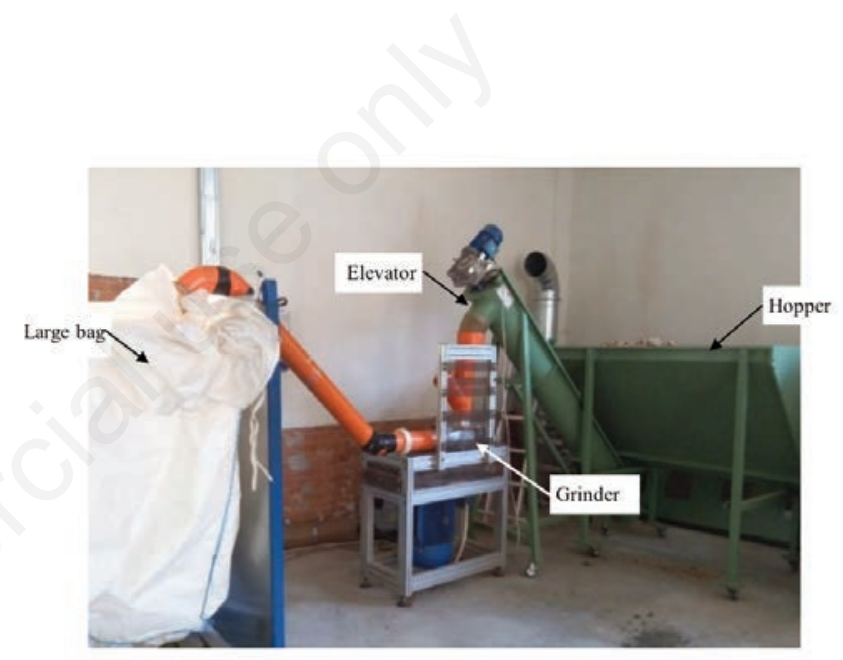

Figure 4. Experimental plant for the refining process. The grinder prototype is positioned between the feeding devices (hopper and elevator) and the big bag.

Table 2. Chipper settings considered for the experiments.

\begin{tabular}{lccc} 
& Description & Setting no. 1 (current) & Setting no. 2 (alternative) \\
Factor 1 & Mesh of the chipper grid & $30 \times 30 \mathrm{~mm}$ & $50 \times 50 \mathrm{~mm}$ \\
Factor 2 & Log forward speed & Low & High \\
\hline Factor 3 & Chippers blade-anvil distance & Minimum & Maximum \\
\hline
\end{tabular}

Table 3. Particle size distribution of the wood chips obtained with the two chipper settings (see Table 2) and after the sieving process.

\begin{tabular}{|c|c|c|c|c|c|c|}
\hline & & Sample 1 & Sample 2 & Sample 3 & Mean \% & Std. dev. \\
\hline Setting 1 & $\begin{array}{l}\text { Total weight (kg) } \\
\text { Weight (in } \mathrm{kg} \text { ) of particles }>10 \times 10 \\
\text { Weight (in } \mathrm{kg} \text { ) of particles }>5 \times 5 \\
\text { Weight (in } \mathrm{kg} \text { ) of particles }>2.5 \times 2.5 \\
\text { Weight (in } \mathrm{kg} \text { ) of particles }<2.5 \times 2.5\end{array}$ & $\begin{array}{l}3.200 \\
0.275 \\
1.635 \\
0.935 \\
0.355\end{array}$ & $\begin{array}{l}3.620 \\
0.435 \\
1.705 \\
0.945 \\
0.535\end{array}$ & $\begin{array}{l}3.590 \\
0.435 \\
1.485 \\
1.215 \\
0.455\end{array}$ & $\begin{array}{c}- \\
11.0 \% \\
46.3 \% \\
29.7 \% \\
12.9 \%\end{array}$ & $\begin{array}{l}- \\
2.01 \% \\
4.89 \% \\
3.89 \% \\
1.85 \%\end{array}$ \\
\hline Setting 2 & $\begin{array}{l}\text { Total weight }(\mathrm{kg}) \\
\text { Weight (in } \mathrm{kg} \text { ) of particles }>10 \times 10 \\
\text { Weight (in } \mathrm{kg} \text { ) of particles }>5 \times 5 \\
\text { Weight (in } \mathrm{kg} \text { ) of particles }>2.5 \times 2.5 \\
\text { Weight (in } \mathrm{kg} \text { ) of particles }<2.5 \times 2.5\end{array}$ & $\begin{array}{l}3.905 \\
1.250 \\
1.945 \\
0.425 \\
0.285\end{array}$ & $\begin{array}{l}2.420 \\
0.725 \\
1.215 \\
0.335 \\
0.145\end{array}$ & $\begin{array}{l}3.450 \\
1.630 \\
1.075 \\
0.565 \\
0.180\end{array}$ & $\begin{array}{c}- \\
36.9 \% \\
43.3 \% \\
13.6 \% \\
6.24 \%\end{array}$ & $\begin{array}{c}- \\
9.44 \% \\
10.88 \% \\
2.75 \% \\
1.05 \%\end{array}$ \\
\hline
\end{tabular}


quite different. Moreover, the comparison between the particle size distribution obtained with the new proposed process and that of the current process (Table 4) showed that, despite finer particles remained at comparable levels, other size ranges were different (Figure 8).

\section{Comparison of the two processes in terms of energy consumption}

Through the experiments performed with the chipper, we determined the fuel consumption for the two investigated settings (Table 2). Table 5 shows the diesel fuel consumption, the measured material flow rate of the chipper and the specific energy consump-

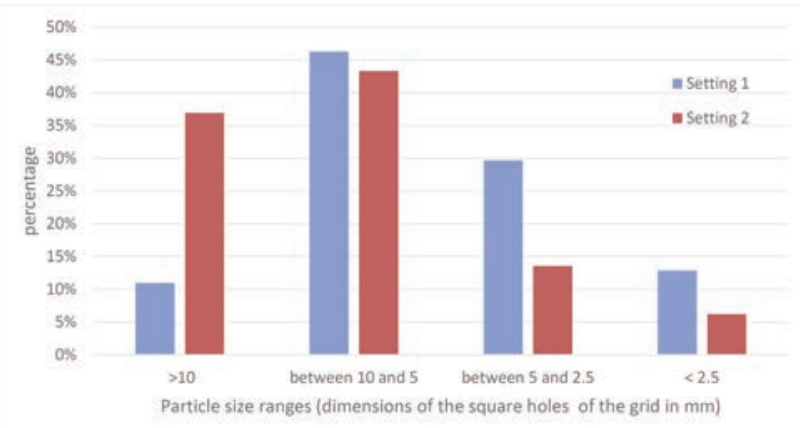

Figure 5. Particle size distributions obtained with the two chipper settings (see Table 2 ).

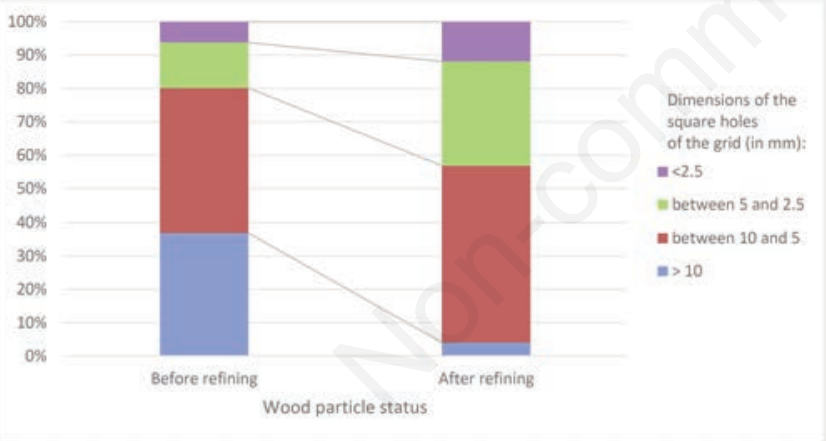

Figure 6. Particle size distributions before and after the refining process. tion per $\mathrm{sm}^{3}$ of produced chips. In particular, a calorific value of 43 $\mathrm{MJ} / \mathrm{kg}(10 \mathrm{kWh} / \mathrm{L})$ for diesel fuel was used to convert the measured consumption (in litres) into the required units.

Focusing on the current process (i.e., considering Setting 1 from Table 2), and considering the possible ranges of product fractions (Materials and methods section), we performed a preliminary assessment of the energy consumption for both the best and the worst cases (Table 2). As highlighted in Materials and methods section, the energy consumption of the dryer and the sieve were already available to the consortium.

The experiments performed with the grinder prototype allowed us to determine an average specific energy consumption of 4.8 $\mathrm{kWh} / \mathrm{sm}^{3}$ of processed wood chips. More specifically, energy consumption depended on the specific configuration used to transform the wood chips obtained from Setting 2 (Table 3 ) into the particles shown in Table 4 and Figure 7B. The specific grinder settings allowed for a limited production rate (about $0.7 \mathrm{sm}^{3} / \mathrm{h}$ ) and one
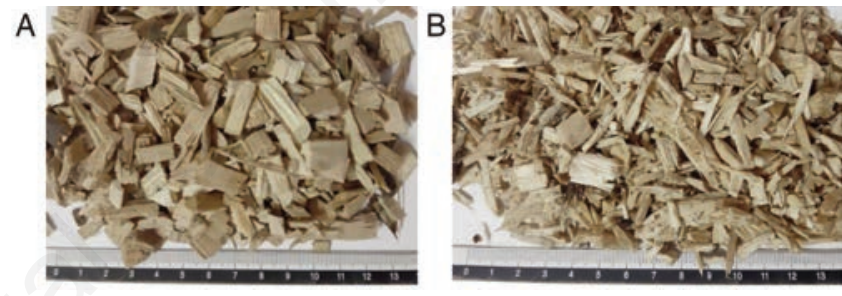

Figure 7. Wood mulch obtained with the current process (A) and with the new proposed one (B). The main length scale is in $\mathrm{cm}$.

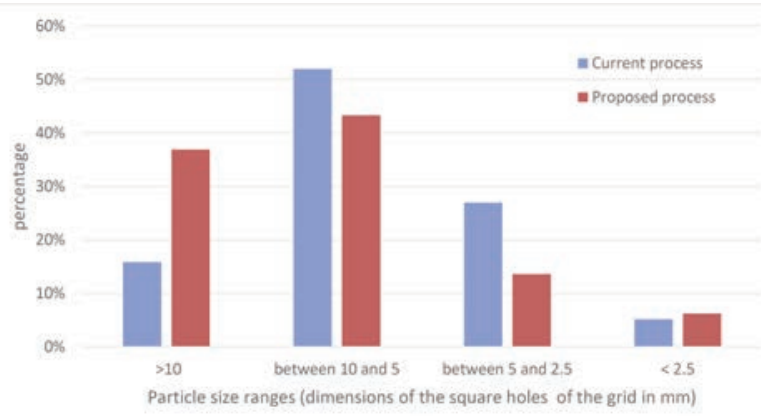

Figure 8. Particle size distributions obtained with the current process and the proposed one.

Table 4. Particle size distributions obtained with the new and the current processes.

\begin{tabular}{|c|c|c|c|c|c|c|}
\hline & & Sample 1 & Sample 2 & Sample 3 & Mean \% & Std. dev. \\
\hline \multirow[t]{5}{*}{ New process } & Total weight $(\mathrm{kg})$ & 1.005 & 1.079 & 1.034 & - & - \\
\hline & Weight (in $\mathrm{kg}$ ) of particles $>10 \times 10$ & 0.042 & 0.046 & 0.039 & $4.07 \%$ & $0.26 \%$ \\
\hline & Weight (in $\mathrm{kg}$ ) of particles $>5 \times 5$ & 0.544 & 0.524 & 0.574 & $52.7 \%$ & $3.68 \%$ \\
\hline & Weight (in $\mathrm{kg}$ ) of particles $>2.5 \times 2.5$ & 0.300 & 0.363 & 0.315 & $31.3 \%$ & $2.04 \%$ \\
\hline & Weight (in $\mathrm{kg}$ ) of particles $<2.5 \times 2.5$ & 0.119 & 0.146 & 0.106 & $11.9 \%$ & $1.64 \%$ \\
\hline \multirow[t]{5}{*}{ Current } & Total weight $(\mathrm{kg})$ & 0.966 & 1.012 & 0.91 & - & - \\
\hline & Weight (in $\mathrm{kg}$ ) of particles $>10 \times 10$ & 0.1575 & 0.161 & 0.14 & $15.87 \%$ & $0.46 \%$ \\
\hline & Weight (in $\mathrm{kg}$ ) of particles $>5 \times 5$ & 0.525 & 0.4945 & 0.48 & $51.99 \%$ & $2.82 \%$ \\
\hline & Weight (in $\mathrm{kg}$ ) of particles $>2.5 \times 2.5$ & 0.2415 & 0.299 & 0.24 & $26.97 \%$ & $2.33 \%$ \\
\hline & Weight (in $\mathrm{kg}$ ) of particles $<2.5 \times 2.5$ & 0.042 & 0.0575 & 0.05 & $5.17 \%$ & $0.72 \%$ \\
\hline
\end{tabular}


should bear in mind that the prototype was originally designed and built only for preliminary experimental purposes. Nevertheless, the information gathered in the experiments allowed us to obtain an initial estimate of the energy consumption of the new process. In particular, it was estimated that for each steric cube meter of processed raw material, the chipper consumption was $4.5 \mathrm{kWh}$ and the grinder consumption was $4.8 \mathrm{kWh}$ (i.e. a total consumption of 9.3 $\mathrm{kWh} / \mathrm{sm}^{3}$ )

The power consumption of the new process, compared with the chipping and sieving process, is markedly lower. However, the data cannot be directly compared with those in Table 6 , because the current process produces two different products (i.e., mulch and P45-M20 wood chips), whereas the alternative process was specifically aimed at obtaining $100 \%$ wood mulch. Therefore, for a valid comparison, we transformed the energetic consumption values into energetic costs by considering the current prices of diesel fuel and electricity. Notably, due to climatic conditions (in winter, the temperature can rapidly fall below $0^{\circ} \mathrm{C}$ at approximately 1000 meters above sea level), the chipper was fed with arctic diesel fuel, which is currently sold at $1.5 € / \mathrm{L}$. As to electricity, the current price of $0.15 € / \mathrm{kWh}$ was used, and the coarse wood chips used to feed the dryer are currently sold at approximately $69 € / \mathrm{t}$.

For a consumption of $25 \mathrm{~kg}$ of coarse chips for drying $1 \mathrm{sm}^{3}$ of processed chips (see Current production process adopted by the consortium section), the energy cost of the drying process was approximately $1.75 €$ for each steric cubic meter of dehumidified chips. Therefore, according to the production ranges in Table 6 (i.e., best case and worst case), we calculated the decrease in gross economic value of the processed wood chips with the current process (Equation 2):

$R V=S V-D C-E C-W C$

where $R V$ is the reduced gross value of the processed chips; $S V$ is the starting gross value; and $D C, E C$ and $W C$ are the costs of diesel fuel, the electricity and the wood chips (used as fuel for the oven), respectively, in $€ / \mathrm{sm}^{3}$ (intended as euros per steric cubic meter of wood chips processed in the entire process). However, while the diesel fuel consumption was related to all processed raw materials, electricity consumption was related to both the first sieving and the second sieving (Figure 1). On the contrary, the consumption of coarse wood chips used as fuel for the drying oven was only related to the oversized fraction of the processed particles. Accordingly, the electricity consumption and the drying energy consumption can be expressed as follows (Equations 3 and 4):

$E C=T E C(1+O F)$

$W C=T W C \times O F$

where $T E C$ and $T W C$ are electricity consumption and drying energy consumption (from coarse wood chips), respectively, per $\mathrm{sm}^{3}$ of processed chips, and $O F$ is the oversized fraction of material which underwent further sieving and drying.

Equations 2, 3 and 4 can also be applied to the new proposed process, in which $O F$ is equal to zero, and electricity consumption refers only to the grinding phase.

Therefore, the actual energy costs are those in Table 7, in which the reduced gross value of the processed material is reported for both investigated processes.

Importantly, for these preliminary evaluations, the energetic consumption of accessories, such as feeding screws and/or agitators were not considered, because they were assumed to be comparable between the investigated processes. Under this assumption, the results shown in Table 7 demonstrate that the new proposed process offers greater economic value for the processed material, mainly because all of it is transformed into wood mulch. Indeed, according to Table 1, wood mulch has a higher economic value than P45-M20 wood chips.

\section{Comparison of the two processes in terms of $\mathrm{CO}_{2}$ emis- sions}

To perform a preliminary comparison between the investigated processes in terms of $\mathrm{CO}_{2}$ emissions, we used conversion factors from the literature to determine $\mathrm{CO}_{2}$ emissions starting from fuel consumption (Zadek and Schulz, 2010). As to the emissions of diesel fuel, 1 litre of fuel produces approximately $2.8 \mathrm{kgCO}$, whereas for electricity we used the current conversion factor of $0.31 \mathrm{kgCO}_{2} / \mathrm{kWh}$, which was estimated for this specific region (Corradi et al., 2019). In contrast, the combustion of wood chips can be considered $\mathrm{CO}_{2}$ neutral (Kažimírová and Opáth, 2016); this means that $\mathrm{CO}_{2}$ emissions from the burnt wood are equivalent to the $\mathrm{CO}_{2}$ converted by the original plant. Therefore, on the basis of the observed power consumptions and the data listed in Tables 5 and 6 , we determined the $\mathrm{CO}_{2}$ emissions from the main machinery involved in the investigated processes. The related values are reported in Table 8, which shows that the new proposed process is

Table 5. Fuel consumption of the chipper in the two considered settings (see Table 2). The equivalent energy consumption is obtained by considering a calorific value of $43 \mathrm{MJ} / \mathrm{kg}(10 \mathrm{kWh} / \mathrm{L})$ for the Diesel fuel (Iliev and Mitev, 2019).

\begin{tabular}{lcccc} 
& Consumption for 3 big-bags & Consumption for $\mathrm{sm}^{3}$ & Flow rate & Energy consumption \\
Setting 1 & 3 litres & 0.67 litres & $15.6 \mathrm{sm}^{3} / \mathrm{h}$ & $6.7 \mathrm{kWh} / \mathrm{sm}^{3}$ \\
Setting 2 & 2 litres & 0.45 litres & $22.4 \mathrm{sm}^{3} / \mathrm{h}$ & $4.5 \mathrm{kWh} / \mathrm{sm}^{3}$ \\
\hline
\end{tabular}

Table 6. Energy consumptions estimated for the current process. The values refer to the steric cube meters of raw material introduced in the whole process.

\begin{tabular}{|c|c|c|c|c|c|c|c|c|}
\hline & & duct fract & & & Energy & Imptior & $\mathrm{Wh} / \mathrm{sm}^{3}$ & \\
\hline & Mulch & P40-M20 & Waste & Chipper & Sieve 1 & Dryer & Sieve 2 & Total \\
\hline Best case & $85 \%$ & $15 \%$ & $0 \%$ & 6.7 & 0.6 & 14.9 & 0.09 & 22.3 \\
\hline Worst case & $70 \%$ & $25 \%$ & $5 \%$ & 6.7 & 0.6 & 24.8 & 0.15 & 32.3 \\
\hline
\end{tabular}


comparable to the current process, but is characterized by a completely different distribution of the $\mathrm{CO}_{2}$ sources.

Indeed, while the current process is prevalently dependent on fossil fuel ( $88 \%$ ), the new proposed process is characterized by a more balanced distribution (i.e. $47 \%$ from electricity and $53 \%$ from fossil fuel).

\section{Discussion}

\section{Results}

The experiments presented in this article allowed us to preliminarily compare two processes for the production of wood mulch in terms of particle size distribution, energy consumption (and related effects on the gross product value) and $\mathrm{CO}_{2}$ emissions. The chipping and sieving procedure currently adopted by the consortium was found to produce more regular particle size distributions, mainly because of the sieving process. However, to maximize the fraction of the desired particles, the chipper was set up with a configuration that reduces its effectiveness, thus increasing power consumption (Table 5). Moreover, it was not possible to transform all the raw material into wood, mainly because of a variable percentage of oversized particles. Even if the oversized chips were processed with a parallel process aimed at improving their value, the energy costs would not be justified if compared to the actual economic improvement. On the contrary, the alternative process allowed all the processed raw material to be converted into wood mulch, and the specific setting of the chipper together with the limited power consumption of the considered grinder prototype led to greater economic advantages (Table 7). In this case, the particle size distribution was more irregular than that obtained with the current process (Figure 7), however, the first impressions of nursery users confirmed that the product could be successfully used for weed control in pots. As to $\mathrm{CO}_{2}$ emissions, the two processes are currently comparable (Table 8 ), but the alternative process uses a more balanced distribution between electricity consumption and diesel fuel consumption. This makes it possible to decrease greenhouse gas emissions by using electricity generated from renewable sources, such as wind power or solar power (Rajput et al., 2018).
Moreover, the $\mathrm{CO}_{2}$ impact of the arctic diesel fuel could be reduced by using bio-fuels (Coronado et al., 2009), but in the specific region considered in this work, this replacement would be possible only in warmer seasons, owing to the low temperatures, which could lead to performance and/or fuel crystallization problems.

\section{Limits of the work}

Although the results presented in this article provide fundamental indications on how to improve the production of wood mulch for specific potting applications, the work has several limitations with implications which are worth being discussed. Accordingly, we provide a comprehensive discussion of the limits concerning both the experimental conditions and the related economic evaluations.

Firstly, these results cannot be directly generalized, because the experiments were performed only with the specific machinery available to the consortium. In particular, the chipper (and the related tractor) had limited power, therefore it would not be possible to increase further the mesh size of the chipper screen, thus limiting the differences in the particle size distributions obtained with the investigated chipper settings (Table 3). However, according to the literature, the higher the mesh size of the chipper screen, the higher the average chip size, and the lower the fuel consumption (Nati et al., 2010). Therefore, the advantages observed for the new proposed process were underestimated, because a sufficiently powered hipper would allow for greater screen mesh sizes (e.g., $80 \mathrm{~mm} \times 80 \mathrm{~mm}$ ), thus further reducing diesel fuel consumption. Additionally, the power consumption of the grinder could also be reduced, because the exploited prototype was not designed and optimized for the production of mulch or microchips (Fiorineschi et al., 2020).

Therefore, the results outlined in this article provide only a preliminary indication of the economic and ecological impacts of two processes for the transformation of wood logs from conifer trees into mulch suitable for potting. Indeed, a comprehensive analysis should consider additional parameters and more detailed assessments (Sacchelli et al., 2013) that are currently outside the scope of this work. The two investigated processes were actually implemented in an experimental setting and remain to be optimized. Given the cost of the machinery required for the new proposed pro-

Table 7. Comparison of the energy costs of the two considered processes. The values refer to the steric cube meters of processed raw material, and are used to calculate the reduction of the gross economic value that can be extracted from the processed wood.

\begin{tabular}{|c|c|c|c|c|c|c|}
\hline & & $\begin{array}{l}\text { Diesel } \\
\text { costs } \\
\left(€ / \mathrm{sm}^{3}\right)\end{array}$ & $\begin{array}{l}\text { Electric energy } \\
\text { costs } \\
\left(€ / \mathrm{sm}^{3}\right)\end{array}$ & $\begin{array}{l}\text { Wood chips energy } \\
\text { costs } \\
\left(€ / \mathrm{sm}^{3}\right)\end{array}$ & $\begin{array}{c}\text { Gross product } \\
\text { value } \\
\left(€ / \mathrm{sm}^{3}\right)\end{array}$ & $\begin{array}{l}\text { Reduced gross } \\
\text { product value } \\
\left(€ / \mathrm{sm}^{3}\right)\end{array}$ \\
\hline Current process & $\begin{array}{l}\text { Best case } \\
\text { Worst case }\end{array}$ & 1.01 & $\begin{array}{l}0.10 \\
0.11\end{array}$ & $\begin{array}{l}0.24 \\
0.40\end{array}$ & $\begin{array}{l}46.3 \\
41.3\end{array}$ & $\begin{array}{l}44.9 \\
39.8\end{array}$ \\
\hline New process & & 0.68 & 0.72 & - & 50 & 48.6 \\
\hline
\end{tabular}

Table 8. $\mathrm{CO}_{2}$ emissions from the main machinery involved in the investigated processes.

\begin{tabular}{|c|c|c|c|}
\hline & $\begin{array}{l}\mathrm{CO}_{2} \text { from electric power } \\
\left(\mathrm{kg}_{\mathrm{CO} 2} / \mathrm{sm}^{3}\right)\end{array}$ & $\begin{array}{l}\mathrm{CO}_{2} \text { from Diesel fuel } \\
\left(\mathrm{kgCO}_{2} / \mathrm{sm}^{3}\right)\end{array}$ & $\begin{array}{l}\text { Total } \mathrm{CO}_{2} \text { emissions } \\
\left(\mathrm{kg}_{\mathrm{CO}} / \mathrm{sm}^{3}\right)\end{array}$ \\
\hline Current process B.C. & 0.29 & 2.21 & 2.5 \\
\hline Current process W.C. & 0.35 & 2.68 & 3.03 \\
\hline New process & 1.26 & 1.41 & 2.67 \\
\hline
\end{tabular}


cess (Figure 2), it is currently impossible to make a reliable estimate, because the grinder was a single prototype and its related production costs were those for the proof of concept and might, therefore, be very different from those of the final system (Carfagni et al., 2018). However, the grinder project remains under development, and the system will need to be redesigned at a larger scale to comply with real process requirements (which remain to be identified by the consortium staff). In particular, both particle size distributions obtained with the two processes (Figure 7) appear to be acceptable for this specific application, as they allow for good distribution in pots and the required soil transpiration. However, a detailed investigation of the required particle size distributions would better support the design of a more efficient process and its related technology.

\section{Directions for future experiments and redesign of the process}

Each highlighted limitation provides a potential direction for future developments, which, however, may require new investment of resources. Indeed, to perform more extended tests on wood mulch production, both the machinery and the experimental conditions must be improved.

In the near future, additional tests should be performed with larger chippers in which parameters can be increased (Table 2) such as the mesh size of the chipper screen, the anvil-blade distance and the forward speed of wood logs. Larger chips and reduced fuel consumption are expected, but it will be important to test the actual capability of the grinder to comminute larger wood pieces.

Concurrently, in-field application of mulch samples must be performed with different particle size distributions to identify the best configuration and provide precise indications for the redesign and the optimization of the process and the related machinery. To that end, a more comprehensive characterization of the particle size distribution is needed, e.g., through Rosin-Rammler particle size analysis (Lynch and Rowland, 2005) (which was not possible in this work, because the handmade, manually powered selective sieve did us not allow to make repeatable and reliable measurements).

Additional experiments should also be performed with different moisture contents of the processed wood. Indeed, hammer mills require more energy when processing moist wood chips (Obernberger and Thek, 2010). This condition is valid also for different grinding/comminution systems (e.g., wood chippers), but it is unclear if it fits with the adopted grinder prototype. Moreover, for traditional grinders, the grinding energy requirements are influenced by the wood species (Esteban and Carrasco, 2006). Therefore, specific tests should be performed with the grinder to control the effects of the species of wood, particle size reduction rate and moisture content.

Accordingly, although conifers are the preferred species, owing to their relatively lower economic value, a comparison of process costs derived from different species might yield interesting results. In fact, there is one non-negligible problem with conifers, which could hinder export in some countries: conifers (and, to a lesser extent, broad-leaved trees) tend to be infected by dangerous nematodes (e.g., Aphelenchoides bicaudatus, Aphelenchoides hylurgi, Aphelenchoides bicaudatus, Bursaphelenchus minutus, Bursaphelenchus tusciae Bursaphelenchus cfr. antoniae and Tylenchus sp.) (Tarasco et al., 2015). Clearly, if logs are infested, the related wood chips will also be infested. Unfortunately, wood mulch (since it is made of wood chips) can be a vehicle for nema- tode transmission, and some countries do not allow importation of pots with nematode infected mulch. Indeed, some of these organisms are plant parasites that can attack woody tissues under the bark, whereas others can be dangerous for roots. Therefore, the presence of some species of nematodes in pots can be a source of serious problems in terms of plant nutrition and/or wood damage. If the presence of nematodes is detecting by customs, the plants can undergo a quarantine.

Consequently, the final process should necessarily include a sterilization phase, but the most appropriate technology must be selected to ensure the economic feasibility of the process. Indeed, high temperatures (if maintained for the required time) can actually kill and/or inactivate nematodes (Allen et al., 2017), but heatbased processes can be too costly in relation to the relatively low value of the final product. However, other processes could be investigated, which might require lower power consumption (e.g., ultrasound or microwaves). Therefore, the problem of nematode sterilization is one of the main future research directions for this project, which is expected to provide fundamental information and guidance for the design and the optimization of the final production plant.

\section{Conclusions}

This article describes the assessment of two processes for the production of mulch as a potential substitute for herbicides in plant production. A set of experiments was performed in a consortium for biomass research and production in the Tuscan-Emilian Apennine. The objective was to measure and compare the performance of the currently used process with an innovative alternative based on a new grinding technology. Despite the limitations in the experimental approach, the collected outcomes revealed several findings. Indeed, the performed experiments allowed to compare preliminarily two processes for the production of wood mulch in terms of particle size distribution, energy consumption and $\mathrm{CO}_{2}$ emissions. The current procedure produced more regular particle size distributions, but with higher power consumption. Additionally, this process was unable to convert the totality of the raw material in the desired product. In contrast, the alternative process allowed to convert all the processed wood into mulch, with greater economic advantages. However, the particle size distribution was more irregular, but the first impressions from the users confirmed that the product could be successfully used for weed control in pots.

Regarding $\mathrm{CO}_{2}$ emissions, the two processes are currently comparable, but the alternative process uses a more balanced distribution between electricity consumption and diesel fuel consumption. This aspect makes it possible to reduce greenhouse gas emissions by using renewable sources, such as wind power or solar power.

Future developments will involve the design and implementation of a prototype of the new process according to the specific requirements for nursery applications. This task will also involve addressing sterilization problems to eliminate microorganisms that are dangerous to plants, an aspect that was not considered in this study.

\section{References}

Acquavella J.F., Alexander B.H., Mandel J.S., Gustin C., Baker B., Chapman P. 2004. Glyphosate biomonitoring for farmers and 
their families: Results from the farm family exposure study. Environ. Health Perspect. 112;321-6.

Allen E., Noseworthy M., Ormsby M. 2017. Phytosanitary measures to reduce the movement of forest pests with the international trade of wood products. Biol. Invasions 19:3365-76.

Carfagni M., Fiorineschi L., Furferi R., Governi L., Rotini F. 2018. The role of additive technologies in the prototyping issues of design. Rapid Prototyp. J. 24:1101-16.

Chalker Scott L. 2015. Using arborist wood chips as landscape mulch. Washington State University, Washington, DC, USA.

Coronado C.R., de Carvalho J.A., Silveira J.L. 2009. Biodiesel $\mathrm{CO} 2$ emissions: A comparison with the main fuels in the Brazilian market. Fuel Process. Technol. 90:204-11.

Corradi O., Baumann O., Hinkle T., Collignon M., Qvist F. 2019. Live $\mathrm{CO} 2$ emissions for electricity consumption. Available from: www.electricitymap.org Accessed: 12 December 2019.

Esteban L.S., Carrasco J.E. 2006. Evaluation of different strategies for pulverization of forest biomasses. Powder Technol. 166:139-51.

Febbi P., Costa C., Menesatti P., Pari L. 2013. Determining wood chip size: Image analysis and clustering methods. J. Agricult. Engine. 44:519-21.

Fiorineschi L., Cascini G., Rotini F., Tonarelli A. 2020. Versatile grinder technology for the production of wood biofuels. Fuel Process. Technol. $197 . \quad$ Available at:https://doi.org/10.1016/j.fuproc.2019.106217

Fiorineschi L., Frillici F.S., Gregori G., Rotini F. 2018. Stimulating idea generation for new product applications. Int. J. Innovat. Sci. 10:454-74.

Haque N., Somerville M. 2013. Techno-economic and environmental evaluation of biomass dryer. Procedia Engine. 56:6505.

Iliev S., Mitev E. 2019. Modeling and investigation of a diesel engine with methanol additives. IOP Conf. Ser. Materials Sci. Engine. 614. Available from: https://doi.org/10.1088/1757$899 X / 614 / 1 / 012012$

Kannepalli S., Strom P.F., Krogmann U., Subroy V., Giménez D.,
Miskewitz R. 2016. Characterization of wood mulch and leachate/runoff from three wood recycling facilities. J. Environ. Manage. 182:421-8.

Kažimírová V., Opáth R. 2016. Biomass combustion emissions. Res. Agricult. Engine. 62:S61-S65.

Lynch A.J., Rowland C.A. 2005. The History of Grinding, Society for Mining, Metallurgy, and Exploration, Inc., Littleton, CO, USA. Available from: https://doi.org/Book Review

Nati C., Spinelli R., Fabbri P. 2010. Wood chips size distribution in relation to blade wear and screen use. Biomass Bioener. 34:583-7.

Obernberger I., Thek G. 2010. The Pellet Handbook, Earthscan, London, UK.

Rajput S.K., Gwalior S., Singh O. 2018. Reduction in CO2 emission through photovoltaic system: a case study. 3rd IEEE International Conference on Nanotechnology for Instrumentation and Measurement.

Sacchelli S., Fagarazzi C., Bernetti I. 2013. Economic evaluation of forest biomass production in central Italy: A scenario assessment based on spatial analysis tool. Biomass Bioener. 53:1-10.

Schaller M. (n.d.). Humimeter. Available from: https://www. humimeter.com/it/bioenergia/humimeter-bm1-sostituito/ Accessed: 18 February 2019.

Spinelli R., Pari L., Magagnotti N. 2018. New biomass products, small-scale plants and vertical integration as opportunities for rural development. Biomass Bioener. 115:244-52.

Tarasco E., Clausi M., Rappazzo G., Panzavolta T., Curto G., Sorino R., Oreste M. 2015. Biodiversity of entomopathogenic nematodes in Italy. J. Helminthol. 89:359-66.

Woo H., Han H.S. 2018. Performance of screening biomass feedstocks using star and deck screen machines. Appl. Engine. Agric. 34:35-42.

Zadek H., Schulz R. 2010. Methods for the calculation of CO2 emissions in logistics activities. pp 263-268 in W. Dangelmaier, A. Blecken, R. Delius S. and Klöpfer (Eds.), Advanced manufacturing and sustainable logistics. Springer, Berlin-Heidelberg, Germany. 